\begin{tabular}{c} 
International Journal of Engineering \& Technology, 7 (3.15) (2018) 187-191 \\
International Journal of Engineering \& Technology \\
SPC \\
Website: www.sciencepubco.com/index.php/IJET \\
Research paper \\
\hline
\end{tabular}

\title{
The Nexus between Funding and Research Output: A Case Study in Universiti Teknologi MARA
}

\author{
Caroline Henry ${ }^{1}$, Nor Azura Md Ghani ${ }^{1,2 *}$, Halilah Haron ${ }^{1}$, Umi Marshida Abd Hamid ${ }^{3}$, Ahmad Naqiyuddin \\ Bakar $^{4}$ and Ahmad Taufek Abdul Rahman ${ }^{3,5}$ \\ ${ }^{I}$ Center for Statistical Studies and Decision Sciences, Faculty of Computer and Mathematical Sciences, Universiti Teknologi MA- \\ RA,40450 Shah Alam, Selangor, Malaysia \\ ${ }^{2}$ National Design Centre, Universiti Teknologi MARA,40450 Shah Alam, Selangor, Malaysia \\ ${ }^{3}$ Faculty of Applied Sciences, Universiti Teknologi MARA, Shah Alam, Selangor Darul Ehsan, Malaysia \\ ${ }^{4}$ Faculty of Administrative Science \& Policy Studies, Universiti Teknologi MARA,40450 Shah Alam, \\ Selangor, Malaysia \\ ${ }^{5}$ Institute of Science, Universiti Teknologi MARA, \\ 40450 Shah Alam, Selangor, Malaysia \\ *Corresponding author E-mail: azura@tmsk.uitm.edu.my
}

\begin{abstract}
Financial sustainability has been a continuous problem that Higher Learning Institutions (HLI) have to face. In addition, funding has always played a role in the process of research as many have proven that there is a relationship between funding and research impact. This study highlights the impact of funding on UiTM's research productivity. Publications published by UiTM in 2012 to 2016 from Web of Science (WoS) were used to compare the impact of both funded and unfunded publications. The findings showed that 32.53\% of the publications published from 2007 to 2016 were funded. Funded publications published in high impact journals have higher citations compared to unfunded publications particularly for Medical and Science \& Technology related fields such as Clinical Medicine and Chemistry. This proves that financial assistance is key to drive quality research and produce impactful publications as it indirectly increases the institution's research productivity.
\end{abstract}

Keywords: Research Productivity; Publication; Funding

\section{Introduction}

Universities funding worldwide has been suffering budget cut due to the current situation of the economy. On top of that, universities should have other alternatives other than depend on the fund provided by the government. [1] reported that the operating budgets in 2017 for public universities in Malaysia are reduced by 19 per cent which is RM1.5 billion compared to budget allocated in 2016. [2] reported that some universities are forced to cut the allocation for research activities due to the budget cut leading academicians and students to struggle in raising money to pursue their research. On top of that, this scenario even impacted the universities' teaching and learning processes, for instance, the engineering field is suffering because of rising prices of metal, alloy, wood and chemicals. Moreover, the impact is also greatly felt by the academicians, who are expected to publish their research papers even when allocations are not coming. [3] stated that financial sustainability is the toughest challenge where competition is present among all the institutions in Malaysia. Hence, universities should be less dependent financially to the government and opt for other funding bodies be it locally or internationally.

\section{Literature Review}

Funding is one of the catalysts for research and innovation as it aids the research process for example providing support for graduate assistance, purchase of research materials and allowing researchers to attend conferences that enable networking and other opportunities. Apart from that, research output has a positive correlation with funding whereby with the aid of funding, more research output can be produced. [4] conducted a study using annual reports and audited financial statements for the duration of 2006 until 2011 produced by five (5) Research Universities (RU) in Malaysia which are Universiti Sains Malaysia (USM), Universiti Malaya (UM), Universiti Kebangsaan Malaysia (UKM), Universiti Putra Malaysia (UPM) and Universiti Teknologi Malaysia (UTM). Based on his study, it was found that $70 \%$ of the funding from the five (5) RUs was contributed by the government. [5] found that 12.5 per cent of Iranian publications were funded and the number of funded publications has increased dramatically from 2006 to 2009. The citation impact of funded publications was higher in almost all of the subject fields. The highest number of funded publications belonged to the universities subordinate to The Iranian Ministry of Science, Research and Technology. [6] performed a study screening through the funding acknowledgment section of nanotechnology publications published between the years 2008 and 2009 and reported that outputs from grant spon- 
sored research exhibited higher impact than outputs from nongrant sponsored research. In addition to that, grant sponsored articles are not only more likely to get published in higher ranked journals, but also to generate more research interest in the field as measured by forward citations. The diversity of funding sources have a more variable influence on research impact. The number of funding sources acknowledged in publications is positive on placement in high quality journals, but tends to be concave on received citations, increasing before reaching the optimal number of funding sources, and then decreasing.

Previously, [7] investigated the influence of funding on the output of research papers in the biomedical field. The data set in the study consisted of 12,925 records which were taken from UK papers on gastroenterology published between the years 1988 and 1994. It was found that the number of authors and the number of funding bodies have a substantial influence on the impact of research outputs. The authors also added that the duration of funding may affect the research outputs. [8] did an extend analysis by using time series and found that output based funding has a positive effect on research quality proving [9] whom claimed that the Australian science policy in the early 1990s made a mistake by introducing output based funding whereby the policy stimulated researchers to publish more but at the same time less good papers, resulting in lower total impact of Australian research compared to other countries. In addition, after implementing evaluation systems and performance based funding, Australia not only improved its share of research output but also increased research quality, implying that total impact was greatly increased. [10] performed an econometric study focused on 68 universities and observed no significant relation between funding and research quality. However, [11] who performed a cross country analysis between the US and Canada observed a positive impact of funding on the quality of nanotechnology publications. Following this, [12] conducted an extension study of both previous study and reported that there is significant positive impact of funding on the productivity of the researchers. In Malaysia, [13] conducted a quantitative survey and qualitative focus group interviews and found that there are positive impact of the funding reforms on the Malaysia's public universities.

In Malaysia, the Ministry of Higher Education (MOHE) has established Malaysia's Research Star Award which is aimed to encourage Malaysians to continue their groundbreaking research in their respective fields and advance global science. The Young Researcher Award category was presented recently by MOHE to researchers below 40 years old who produced the world's top five per cent most cited articles. However, as an institution, common university ranking like QS World University Rankings, the Times Higher Education World University Rankings, and the Shanghai Academic Ranking of World Universities are generally weighted heavily towards research output (for example, citations per faculty and number of papers in top journals). The Malaysia Education Blueprint 2015-2025 (Higher Education) uses the QS rankings for reference purposes as it is the oldest global ranking and a ranking that provides a broader perspective, thereby providing the Ministry with a better sense of the system's trajectory. In addition, university ranking serve as a useful yardstick and benchmark as to where an education system's strengths lie, and how it can improve. However, they should not be seen as the definitive measure of quality [14]. Therefore, this study is aimed to investigate the relationship between research funding and research output in UiTM In this paper, by output we only mean publication of research. The case studied here are UiTM articles, reviews and conference proceedings published from 2012 to 2016.

\section{Methodology}

This study will only focused on publications in the Web of Science (WoS) Core Collection as it is the reference source for the latest Malaysia's Research Star Award selection by MOHE.

\section{Step 1: Data Collection}

Figure 1 shows the step-by-step data retrieval from WoS which were then combined together in Excel format for further refinement and analysis in Figure 2. The citation report was also exported separately and merged together. Citation were based on five (5) years publication. Citation behavior varies in different subject fields. Citation per Paper (CPP) was used to measure the citation impact for the publications.

(a) Key in 'univ teknol mara' and select as address with timespan from 2007 to 2016.

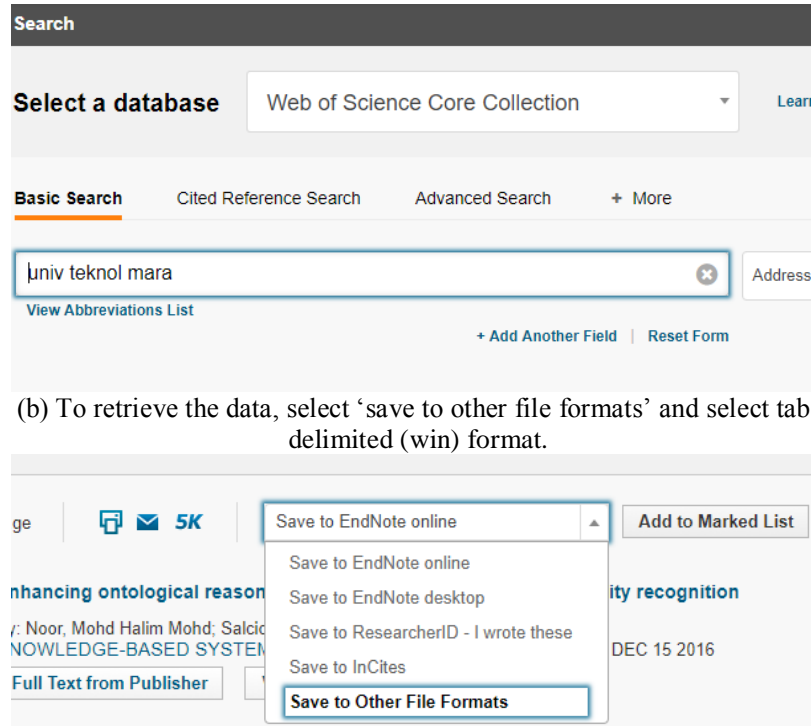

Figure 1: Step-by-step to export publication data from WoS.

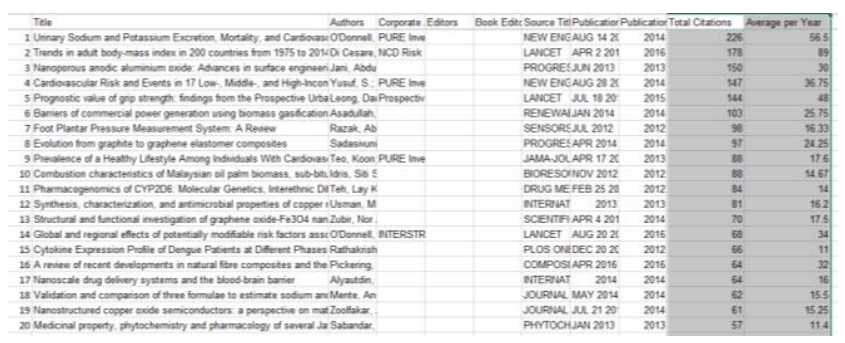

Figure 2: Average Citation per Year are extracted separately from WoS and combined with the other fields.

\section{Step 2: Data Cleaning}

\section{i. Subject Field}

The subject categories of publications were mapped into 22 broad fields covered by [15] database. According to WoS, each journal is assigned to one of 22 research fields, each journal to one field only as in Table 1 . Figure 3 shows the mapping process for each source title.

Table 1: 22 Subject Fields in Research Area Schemes. Source from ISI Essential Science Indicators (ESI) database.

\begin{tabular}{|c|l|c|l|}
\hline No. & \multicolumn{1}{|c|}{ Fields } & No. & \multicolumn{1}{c|}{ Fields } \\
\hline 1 & Agricultural Sciences & 12 & Mathematics \\
\hline 2 & Biology \& Biochemistry & 13 & Microbiology \\
\hline 3 & Chemistry & 14 & Molecular Biology \& Genetics \\
\hline 4 & Clinical Medicine & 15 & Multidisciplinary \\
\hline 5 & Computer Science & 16 & Neuroscience \& Behavior \\
\hline 6 & Economics \& Business & 17 & Pharmacology \& Toxicology \\
\hline 7 & Engineering & 18 & Physics \\
\hline 8 & Environment/Ecology & 19 & Plant \& Animal Science \\
\hline
\end{tabular}




\begin{tabular}{|c|l|c|l|}
\hline 9 & Geosciences & 20 & Psychiatry/Psychology \\
\hline 10 & Immunology & 21 & Social Sciences, General \\
\hline 11 & Materials Science & 22 & Space Science \\
\hline
\end{tabular}

number of publications in Figure 6 continues to increase as research grant acquisition continues to decrease.

\section{ii. Journal Quartile}

In Figure 3, Journal Quartile were mapped together with the journals as in Incites Journal Citation Reports (JCR) obtained from WoS from 2012 until 2016. The ranking for every journal may differ by year, hence there are differences between publications.

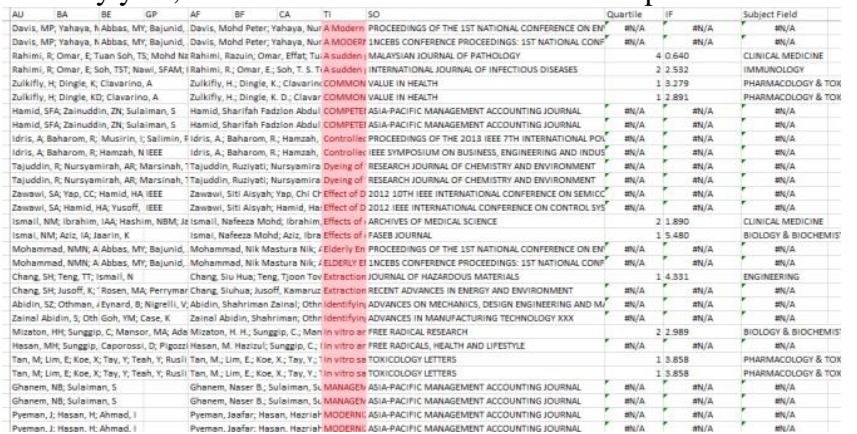

Figure 3: Quartile and Subject Field mapped together with JCR according to the source title.

\section{iii. Funding}

To distinguish between funded and unfunded publications, the "FU" field provided by WoS for each publication was used to create new data by using Excel function as shown in Figure 4. Data that contains value were considered to have funding while blank were categorised as no funding.

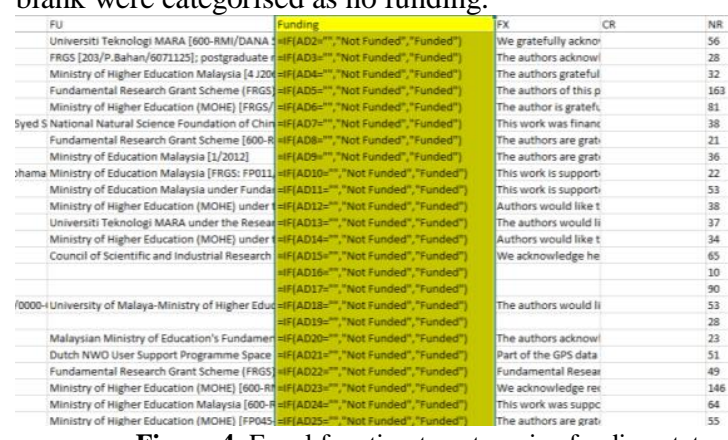

Figure 4: Excel function to categorize funding status.

\section{Step 3: Data Analysis}

Descriptive statistics were performed using Excel to measure the relationship between funding and research output.

\section{Research Findings}

Based on the result for ten (10) years in Table 2, only 32.53\% of UiTM's publication were supported by funding bodies while 67.47

$\%$ were unfunded. Furthermore, the number of publications in 2012 doubled the number of publications in 2011 as in Figure 5. This scenario may have been due to the increase in the acquisition of research grants as in Figure 5. However, there was a decreasing trend in research grant acquisition from different funding sources starting from the year 2012. This study took into account articles, proceeding papers and review papers to study the effects of funding.

Figure 6 shows the trend of funded publication for the past ten (10) years. In 2011, eventhough the number was half the publications in $2012,43.89 \%$ of the publications were funded as opposed to $30.94 \%$ in 2012 . This shows that there are other factors other than funding that drive the number of publications in UiTM. In addition, funding expedite the number of publication as well as citation. In Figure 5, the funding increases in 2016 while in the
Table 2: The number and percentage of funded and unfunded UiTM (2007-2016).

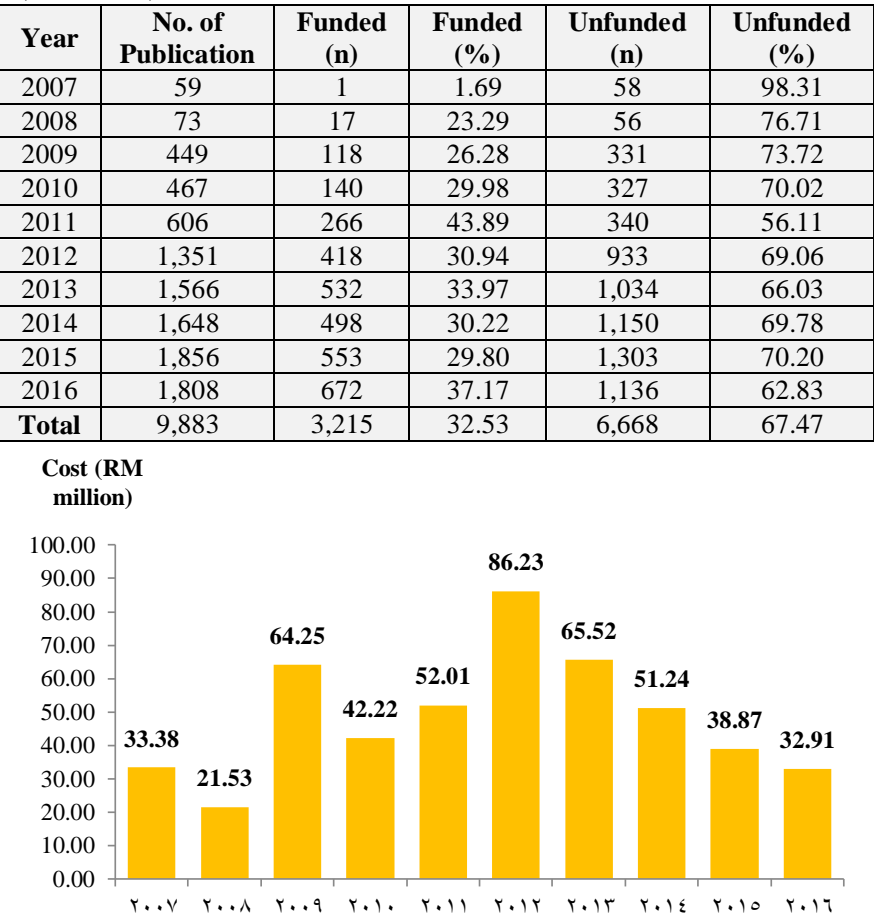

Figure 5: Amount of Research Grant Acquisition for UiTM (2007-2016). Source from Institute of Research Management and Innovation (IRMI), UiTM.

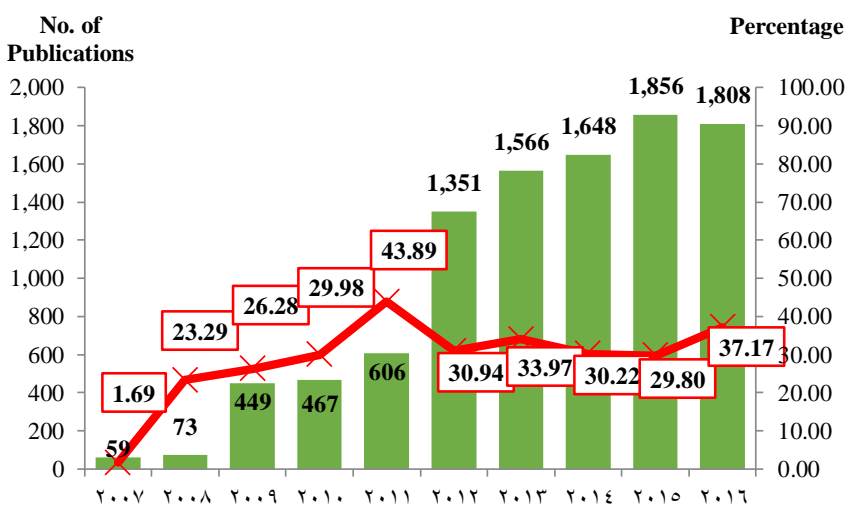

Figure 6: Percentage of funded publications for UiTM (2007-2016).

The research outcome is not necessarily produced in the same year as it would be observed in the following subsequent years. Moreover, funding lessen the burden of researcher where they can get students and sending supervise to publish articles by going to conferences and sending paper to journals. The publications for 2012 until 2016 were analysed to obtain further insight on research productivity.

Table 3 summarises the CPP for funded articles and reviews which are approximately two (2) times more cited compared to unfunded articles and reviews. The CPP for proceedings on the other hand does not differ between both funding status. The most funded publication is article with $65.23 \%$ while the most unfunded publication with $83.40 \%$ are proceeding. Table 4 indicates that Q1 journals are the highest cited quartile whereby funded publications in Q1 are 1.5 more times cited compared to unfunded publications in Q1. Mostly the articles and reviews are funded with $74.28 \%$ while $25.72 \%$ are unfunded.

Table 5 shows the number and percentage of funded and unfunded publications and their citation impact by subject fields. In most Science and Technology fields, funded publications were more 
cited compared to unfunded publications, for example in Chemistry, Clinical Medicine and Mathematics. Funded publications were 4 times more cited compared to unfunded publication in the Mathematics field. While, Chemistry field were 2 times more cited compared to unfunded publication. Other than that, funded publications were 3.5 times more cited compared to unfunded publication in Clinical Medicine. Clinical Medicine is a fast-growing and high impact field, however, with a generally higher publishing fee. Hence, funding is critical for this field to expand and increase productivity and impact. As for the Social Sciences, funding did not appear to have a relationship with CPP value.

Table 3: The number of citation by indexed articles, reviews and proceedings (2012-2016)

\begin{tabular}{|c|c|c|c|c|c|c|c|c|c|}
\hline \multirow{2}{*}{$\begin{array}{c}\text { Document } \\
\text { Type }\end{array}$} & \multicolumn{4}{|c|}{ Funded } & \multicolumn{4}{|c|}{ Unfunded } & \multirow{2}{*}{$\begin{array}{c}\text { Total } \\
\text { Number }\end{array}$} \\
\hline & $n$ & $\%$ & TC & CPP & $n$ & $\%$ & TC & CPP & \\
\hline Article & 1,690 & 65.23 & 9,031 & 1.44 & 901 & 34.77 & 2,525 & 0.66 & 2,591 \\
\hline Review & 70 & 51.09 & 1,065 & 3.84 & 67 & 48.91 & 555 & 2.19 & 137 \\
\hline Proceedings & 913 & 16.60 & 530 & 0.11 & 4,588 & 83.40 & 2,526 & 0.12 & 5,501 \\
\hline
\end{tabular}

Table 4: Indexed articles and reviews (2012-2016) by quartile.

\begin{tabular}{|c|c|c|c|c|c|c|c|c|c|}
\hline \multirow{2}{*}{ Quartile } & \multicolumn{4}{|c|}{ Funded } & \multicolumn{4}{|c|}{ Unfunded } & \multirow{2}{*}{\begin{tabular}{|c|} 
Total \\
Number
\end{tabular}} \\
\hline & $n$ & $\%$ & TC & CPP & $n$ & $\%$ & TC & CPP & \\
\hline 1 & 467 & 77.70 & 5,986 & 3.46 & 134 & 22.30 & 1,257 & 2.33 & 601 \\
\hline 2 & 388 & 75.63 & 2,261 & 1.64 & 125 & 24.37 & 812 & 1.50 & 513 \\
\hline 3 & 352 & 72.13 & 1,162 & 0.81 & 136 & 27.87 & 493 & 0.83 & 488 \\
\hline 4 & 220 & 68.97 & 430 & 0.49 & 99 & 31.03 & 180 & 0.39 & 319 \\
\hline Total & 1,427 & 74.28 & & & 494 & 25.72 & & & 1,921 \\
\hline
\end{tabular}

Table 5: Indexed articles and reviews (2012-2016) by subject fields.

\begin{tabular}{|c|c|c|c|c|c|c|c|c|}
\hline \multirow{2}{*}{ Fields } & \multicolumn{4}{|c|}{ Funded } & \multicolumn{4}{|c|}{ Unfunded } \\
\hline & $n$ & $\%$ & TC & CPP & $n$ & $\%$ & TC & CPP \\
\hline Agricultural Sciences & 46 & 76.67 & 272 & 1.59 & 14 & 23.33 & 58 & 1.08 \\
\hline Biology \& Biochemistry & 101 & 84.87 & 721 & 2.17 & 18 & 15.13 & 151 & 2.64 \\
\hline Chemistry & 222 & 76.82 & 1,839 & 2.17 & 67 & 23.18 & 350 & 1.15 \\
\hline Clinical Medicine & 177 & 69.41 & 1,765 & 3.01 & 78 & 30.59 & 310 & 0.85 \\
\hline Computer Science & 15 & 65.22 & 81 & 1.14 & 8 & 34.78 & 97 & 2.43 \\
\hline Economics \& Business & 0 & 0.00 & 0 & 0.00 & 22 & 100.00 & 144 & 1.45 \\
\hline Engineering & 185 & 77.08 & 1,290 & 1.90 & 55 & 22.92 & 250 & 1.12 \\
\hline Environment/Ecology & 31 & 75.61 & 218 & 1.71 & 10 & 24.39 & 89 & 2.52 \\
\hline Geosciences & 14 & 66.67 & 118 & 2.02 & 7 & 33.33 & 36 & 1.48 \\
\hline Immunology & 12 & 80.00 & 84 & 1.60 & 3 & 20.00 & 16 & 0.89 \\
\hline Materials Science & 207 & 82.14 & 1,357 & 1.63 & 45 & 17.86 & 340 & 2.16 \\
\hline Mathematics & 3 & 60.00 & 29 & 1.78 & 2 & 40.00 & 5 & 0.45 \\
\hline Microbiology & 16 & 94.12 & 73 & 1.09 & 1 & 5.88 & 15 & 5.00 \\
\hline Molecular Biology \& Genetics & 37 & 97.37 & 172 & 1.24 & 1 & 2.63 & 6 & 3.00 \\
\hline Multidisciplinary & 81 & 81.00 & 419 & 1.25 & 19 & 19.00 & 68 & 0.83 \\
\hline Neuroscience \& Behavior & 12 & 66.67 & 43 & 0.95 & 6 & 33.33 & 12 & 0.63 \\
\hline Pharmacology \& Toxicology & 128 & 73.56 & 808 & 1.62 & 46 & 26.44 & 362 & 1.65 \\
\hline Physics & 87 & 70.16 & 398 & 1.11 & 37 & 29.84 & 202 & 1.13 \\
\hline Plant \& Animal Science & 32 & 80.00 & 142 & 1.04 & 8 & 20.00 & 67 & 1.72 \\
\hline Psychiatry/Psychology & 4 & 40.00 & 12 & 1.02 & 6 & 60.00 & 18 & 0.70 \\
\hline Social Sciences, General & 44 & 46.81 & 132 & 0.81 & 50 & 53.19 & 188 & 0.80 \\
\hline Space Science & 1 & 100.00 & 3 & 1.00 & 0 & 0.00 & 0 & 0.00 \\
\hline
\end{tabular}

\section{Discussion}

The study presented herein investigated the effects of research funding on the citation impact of UiTM's research publications. Financial support from funding bodies in terms of research grants is acknowledged as a factor which can influence overall impact and number of times a publication is cited. In the current age, the nature of scientific research has changed and become more complicated as a result of emerging new specialties and fields. Hence, acquirement of grants and investments definitely could be a key element of success in carrying out scientific research. Despite the economic downturn, UiTM is still publishing at an increasing rate suggesting continuous impact of previously acquired research grants on the number of publications per year. In addition, the research and writing acculturation initiatives conducted consistently have contributed towards increased research productivity towards achieving the agenda of UiTM. Scholarly publication is often being used to measure the productivity of an institution and has been recognized worldwide as a medium through which to expand the social and the knowledge economy. Further research should include data from all the
HLIs in Malaysia and analyse the multiple factors associated with scholarly publication.

\section{Conclusion}

In a nutshell, in the case of UiTM, funded research produce higher number of publications compared to unfunded research. Citation counts were also higher with funding as compared to unfunded publications. Out of the 12 subject fields, Clinical Medicine received the highest citation and shows dependency to funding support. Thus, researchers should seek more funding from private and international sources as well as collaborate with other institutions to gain recognition and produce impactful research output. Moreover, the higher management should allocate financial support for new researchers to cultivate the culture of research among academic staffs.

\section{Acknowledgement}

Authors thank Universiti Teknologi MARA (UiTM) for supporting this study under the 600-IRMI/MyRA 5/3/LESTARI (K) (004/2017) and the Institute of Research 
Management and Innovation (IRMI), UiTM for access to research funding data.

\section{References}

[1] Budget 2017: Public universities suffer almost 20pc spending cut (2016). The Malay Mail Online. Retrieved from http://www.themalaymailonline.com/malaysia/article/budget2017-public-universities-suffer-almost-20pc-spendingcut\#ODU2RByhKVae1hJs.99

[2] Mokhtar, A. (2016). Varsities hit hard by budget cuts. Retrieved from https://www.nst.com.my/news/2016/10/180197/varsitieshit-hard-budget-cuts.

[3] Mustafa, Z. (2017). Research Universities: Catalysts for innovation. New Straits Times. Retrieved from https://www.nst.com.my/education/2017/08/274535/researchuniversities-catalysts-innovation.

[4] Amran, F. H., Rahman, I. K. A., Salleh, K., Ahmad, S. N. S., \& Haron, N. H. (2014). Funding trends of research universities in Malaysia. Procedia-Social and Behavioral Sciences, 164, 126134.

[5] Jowkar, A., Didegah, F., \& Gazni, A. (2011). The effect of funding on academic research impact: a case study of Iranian publications. In Aslib Proceedings (Vol. 63, No. 6, pp. 593-602). Emerald Group Publishing Limited.

[6] Wang, J., \& Shapira, P. (2015). Is there a relationship between research sponsorship and publication impact? An analysis of funding acknowledgments in nanotechnology papers. PloS one, 10(2), e0117727.

[7] Lewison, G., \& Dawson, G. (1998). The effect of funding on the outputs of biomedical research. Scientometrics, 41(1-2), 17-27.

[8] van den Besselaar, P., Heyman, U., \& Sandström, U. (2017). Per-verse effects of output-based research funding? Butler's Aus-tralian case revisited. Journal of Informetrics, 11(3), 905918.

[9] Butler, L. (2003). Explaining Australia's increased share of ISI publications - the effects of a funding formula based on publication counts. Research Policy, 32(1), 143-155.

[10] Payne, A. A., \& Siow, A. (2003). Does federal research funding increase university research output? Advances in Economic Analysis \& Policy, 3(1)

[11] Tahmooresnejad, L., Beaudry, C., \& Schiffauerova, A. (2015). The role of public funding in nanotechnology scientific production: Where Canada stands in comparison to the United States. Scientometrics, 102(1), 753-787.

[12] Ebadi, A., \& Schiffauerova, A. (2016). How to boost scientific production? A statistical analysis of research funding and other influencing factors. Scientometrics, 106(3), 1093-1116.

[13] Ahmad, A. R., Farley, A., \& Kim Soon, N. (2014). Categorisation of public universities funding. Asian Social Science, 10(10), 57-67.

[14] Blueprint, M. E. Blueprint 2015-2025 (Higher Education). (2015). Ministry of Higher Education Malaysia.

[15] ISI Essential Science Indicators (ESI) database (http://ipsciencehelp.thomsonreuters.com/inCites2Live/filterValuesGroup/resear chAreaSchema.html). 
